\title{
THE EVER-CONTEMPORARY CHARACTER OF COLOURS AND INTERIOR DECORATION
}

\author{
Bhawna Vyas \\ National Museum Institute, New Delhi
}

\section{INTRODUCTION}

Colours are, perhaps, as old as the universe is; might be older than that. But, for sure, colours are older than arts and are related to every aspect of human life. A colour gets its identity from the rays it generates. In other words, colours are composed of radiations. Thus, when it is about colours, it is more about science than it is about arts. And science cannot be regional or timebound; it is always universally and timelessly applicable. This character of colours inspired me to write 'The Ever-Contemporary Character of Colours and Interior Decoration' and helped me in taking examples from different periods of history, thus making the research paper interesting. In interior decoration, undoubtedly, line and proportion are the most important elements but it falls to the lot of few to be able to dictate what they desire in these spheres. Most of the people are content to limit their interior decoration activities to colour only, as this can be cheaply applied to the walls and choice of small accessories etc. Moreover, changing the colour also changes the look and ambience of an interior instantly and intensely. It also helps in expressing one's personality in their interior and these can be easily done with colour. Colour, therefore, plays the major part in decorative schemes.

Colour, when talked in context of interior decoration, is an element which one should think for oneself. First, the aspect of the room should be considered; if north, then cheery light-giving colours must be chosen; if dark, then bright colours are best. If the room is very light, then delicate colors may be used and window curtains chosen that will give beautiful reflections. Colours also help a lot in creating an illusion of a bigger, spacious interior when the space is small, or to create a feeling of a high ceiling when it is actually low. In more of such ways, colours can completely transform any interior, its appearance and feel.

Other things that may influence in the colouring of an interior are the present possessions; these should be studied to see if they suggest any colour schemes of which they may form the basis. Don't consider fashion when it comes to interior decoration and choosing the right colour for an interior. It is to be remembered that fashion is a factor which changes constantly, and when something goes out of fashion it usually returns in a different form. For instance, wallpapers are again coming into vogue. They are used differently now, and are made with new effects and new surfaces, and reproductions of the old ones are now done with the spirit and texture of the old and not as adaptations. In contemporary interior decoration, wallpapers with 3-D effect are one of the most popular items.

\section{BROWN}

Some of the most beautiful rooms in existence are decorated in tones of brown, but care must be taken to ensure perfection in that. Various shades of brown are used in wooden work applied an interior; especially for door \& window panels and furnishings. Each shade of brown requires its 


\section{INTERNATIONAL JOURNAL Of RESEARCH -GRANTHAALAYAH \\ A knowledge Repository}

Art

special foil or contrast to claim the approval of persons of taste. Autumn brown, copper-orange brown, chocolate brown, hot brown, grey brown are few of the shades of brown which are used as background or in materials within an interior. Brown is hardly applied to the ceiling or to the walls. It is quite necessary to balance a brown interior with bright or light coloured accessories.

\section{WHITE}

The tranquility and piousness conveyed by white is responsible for its universally accepted association with peace and with Shāntam rasa in Indian Art. White can be so liberally used in an interior and can be so pleasing even if everything in the interior is planned in white. The old saying that white decoration is the last resort of people with no taste can no longer be accepted as true, since a better sense of values has opened up new fields for the use of modern paints, enamels and distempers, with which an infinite variety of surface and tone can be achieved. The wide variety of materials available nowadays makes a white interior more vibrant and doesn't allow a white interior to be monotonous. For instance, use of crystal or white leather in accessories of a white interior only adds to the beauty and pristine look of a room.

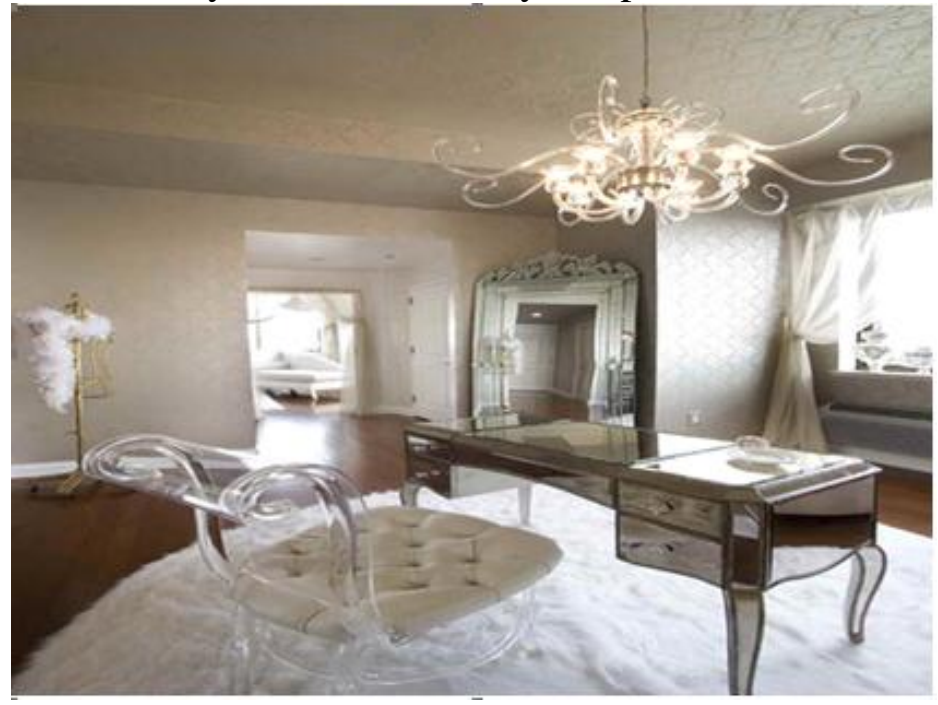

Fig.1 A complete white interior with various shades and materials of white.

Courtesy: http:// www.docxie.com

A point that should be noted in decorating a house entirely in white is the importance of the groundwork. If a warm or creamy tone is required, a red ground should be applied beneath the white, but for a dead white or cool effect grey is the best groundwork. Stippling of one white over another shade will give effects that cannot be gained in any other way. It seems to give a 'satin' quality to the surface, and this is curiously attractive. It is in these details that true distinction in decoration lies, and only by studying them will any real atmosphere be created. 


\section{INTERNATIONAL JOURNAL Of RESEARCH -GRANTHAALAYAH

Art

\section{PINK}

Pink is perhaps one of the most difficult colours to use in interior decoration. The slightest of its excess may be affrighting. A white room can be made to appear pink most successfully by the use of pink window blinds or curtains; but the room must be dead white and not cream or greywhite. Shell pink, with red ornaments or lamp shades, accessories with other complimentary colours makes a charming feature in an interior, and it can be done at very little expense. The pink, here, however, must not be a dull pink.

Pink is best soft and a lot of it, as it is a colour that other colours are apt to drown. When mixed with yellow, brown or gold it is one of the best colours for north rooms where sunny effects are needed and no sun shines.

Combination of pink

Pink and silver is a useful combination; to go with silver, the pink should not be too pale, and it is pleasanter if it has a good shell tone. Pink and gold are apt to cloy, but a little gold with pink is effective. Pink and green will need great care, as the colours must not be too fierce. A greyish green will be found the sweetest to go with any pink. Pink and yellow is cheerful and gives a sunny effect. Pink and black is very modern, and the combination is a little too bizarre to use except on rare occasions. Pink and blue is flowery in its effect, but the blue must be light In tone and should be on the warm purple side. Pink and mauve can be delightful but is difficult to introduce in the permanent features of a room. And so with all colours, pink can be introduced if it is used discreetly.

\section{BLUE}

Blue starts in that indefinite colour which some will call greenish blue, and it passes through many shades to the mauves and slate-greys. Various shades of blue, specially the one associated with Krishna - the blue God, is also used to symbolize vastness and eternity in Indian Art. All these shades are beautiful in their proper places, but the question is - where and when? There are prejudices in the minds of many against blue in decoration, but these prejudices are mostly unreasonable, and due to misunderstanding of the right uses and the right surfaces. Some people imagine that a blue room will not light at night. This is a misconception. It will light beautifully if the lighting is properly treated to suit the tone of colour. There are shades that at night will make the walls of the room disappear and have an effect of distance that is entrancing. The greener blues need brighter lighting and shades of a golden blue for the best effect.

The greatest advantage of a blue interior is that they do not seem to demand any luxurious appointments. It is the easiest colour to treat simply and to furnish with economy, and so is of interest even in the smallest of households or workplaces where beauty is appreciated. 


\section{INTERNATIONAL JOURNAL Of RESEARCH -GRANTHAALAYAH \\ A knowledge Repository}

Art

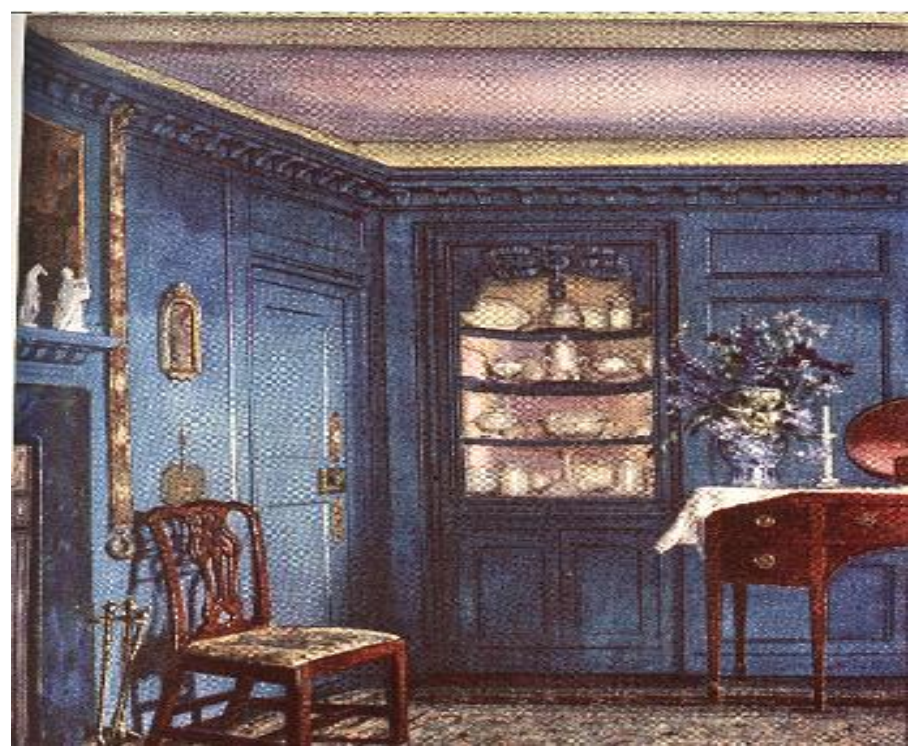

Fig.2 A room with stippled blue walls. Picture by W.B.E. Ranken.

Originally from the book 'Colour and Interior Decoration' by Basil Ionides. Pub: Country Life Ltd., London, 1926.

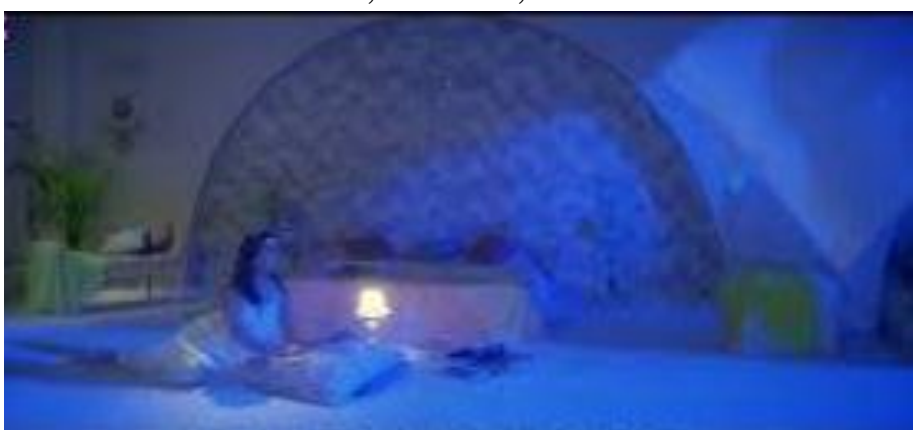

Fig.3 A blue room complimented by use of right light arrangement.

Courtesy: http://www.metacafe.com

\section{GREEN}

Green is the maid-of-all-work among the colours. When there are other colours, and something is needed to go with them, green is always considered safe. Pale greens in a scheme of interior decoration are delightful if one uses curtains and covers to suit, but they are melancholy if destroyed by using unsympathetic additions.

The yellower tones of green are beautiful with pale yellow and cream paintwork. In such a scheme, the curtains might be orange or yellow. Pale pistachio is a delightful colour to use, as also are pale jade and apple-green. There are no dark forms of these colours, they are destroyed when darkened. Pale blue-greens are best for the country, where they will look almost blue and will not clash with the colour of the trees outside. 


\section{INTERNATIONAL JOURNAL Of RESEARCH -GRANTHAALAYAH

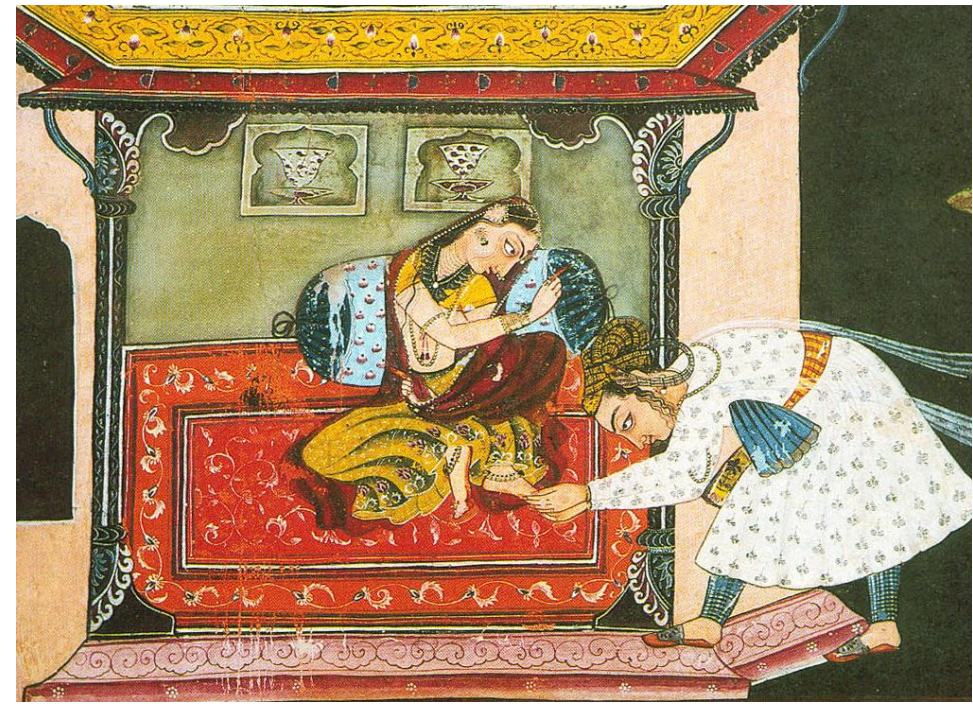

Fig.4 A green interior in a traditional miniature painting, Basohli, 18th Century A.D. Courtesy: Philadelphia Museum of Art, Pennysylvania.

The darker shades of green that are good are very few. Olive is awful, sage is dull, and deep blue-green becomes an inky colour at night; so one is left with a very small choice. Whatever dark green one may be using, one should not have it of a single tone.

In a green room, whether it be dark or light, one does not have the delightful play of reflections that are given by other colours. In a green room all the reflections are mud-coloured. This is probably due to the fact that green is a mixture of yellow and blue, and the addition of a third colour makes a messy effect.

\section{MATERIALS}

Green materials are very useful to create a feeling of freshness in an interior. Chintz with a bright green ground will be found invaluable in any room to cheer it. Green should hardly be used in the country, where ample is supplied by the foliage itself. It is a town colour for west, south or east rooms, and not for the north, unless mixed with other complimentary colours.

\section{GREY}

Grey and all those tones of grey which range from brown to blue are often considered the best for backgrounds. Therefore grey should not be used unless there is something which is to be displayed against it, or some contrasting colour which is to form the real colour note but which is too strong to use in any but small quantities. The pure grey range from the white through all tones to black; the other neutral tints soon cease to be neutral and become brown or blue green or green according to their alliance with these colours. 


\section{INTERNATIONAL JOURNAL Of RESEARCH -GRANTHAALAYAH

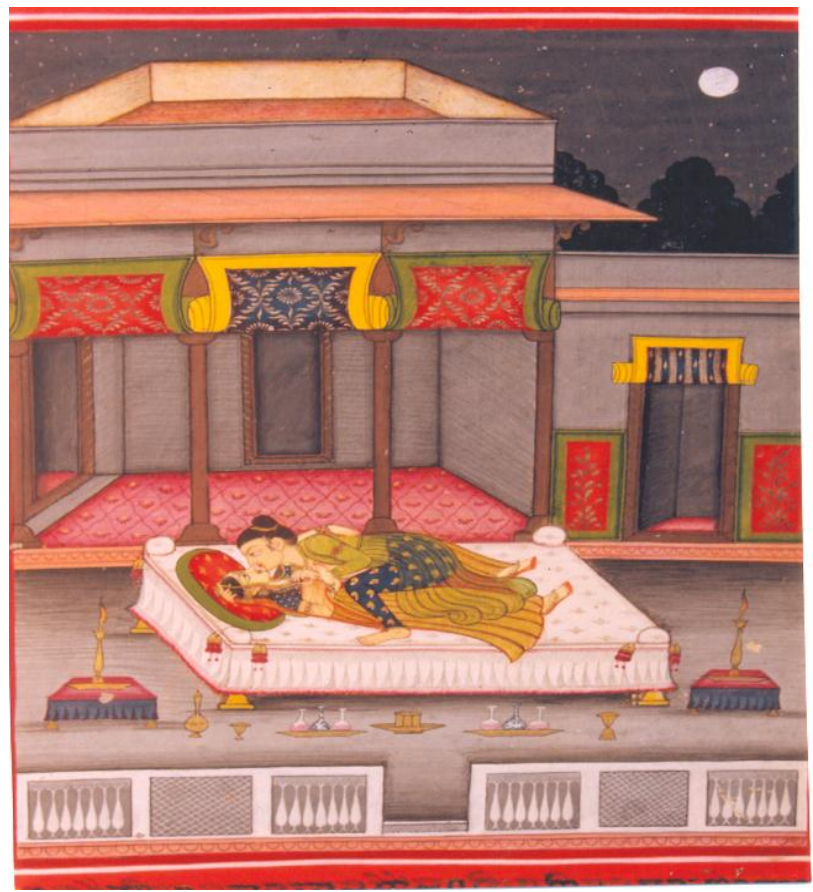

Fig.5 A grey interior from a traditional miniature painting, Datiya, Malwa School of miniature art, Late 18th century A.D. Courtesy: The Allahabad Museum, Allahabad.

A north room should never be grey or it is most depressing, nor should a badly-lighted room, as it will only look dirty; and when working in grey, one must always bear in mind that a dirty effect is to be avoided at all costs.

\section{MATERIALS}

Grey curtains, chair covers and cushions need care. Grey carpets need no care, and can be, and are, put in everywhere where nothing else is called for. One sees so many that one no longer notices them except to remark the good quality of some - or the reverse.

\section{BLACK}

Black in decoration is a shade - not a colour - only to be used where occasion demands. It must not be used except where a scheme calls for it. It may be due to this character of this colour that it is used to symbolize terror or horror. In short, it is hardly used to show any positive emotion or in a cheerful setting. There are many degrees of black, and sorts of these degrees. There are blueblacks and brown-blacks, and there are chalky-grey blacks, dead blacks and glossy blacks - all for different occasions. Some materials are good in black, such as velvet, tiles and wood; others are bad in black, such as satin, distemper, etc. but even the bad ones have their uses.

Many items in the furnishing and decoration of rooms are and have been made in black. There is, for instance, black furniture of papier-mâché, with mother of pearl inlay; and wonderful black 


\section{INTERNATIONAL JOURNAL Of RESEARCH -GRANTHAALAYAH \\ A knowledge Repository}

Art

lacquer. But neither of these should have a black background, as the degrees of black in the articles and the setting will never agree. Such pieces have their own special place.

Slate is one of the nicest black materials, and man tones of black, or nearly black, can be found. It can be carved in a delightful manner - how delightful, one may see in Cornwall ${ }^{1}$, where it is used for tombs, and looks like beautifully embossed lead. Black picture-frames need great care. They will often ruin a picture if too near it without a mount, and they will form spots in the decoration of an interior.

\section{YELLOW}

Yellow, sunshine, gaiety - all these go together, but yellow must be bright for the purpose. At times, it is used to symbolize divinity, amazement and wonder in Indian art. If not bright, yellow loses its shiny and gaiety effect. It is a most useful colour for northern aspects and for dark places. A light room facing north may be pale yellow and delicate, but as the room becomes darker, so should the yellow become more orange and brilliant. A strong orange is not pleasant in a very light interior.

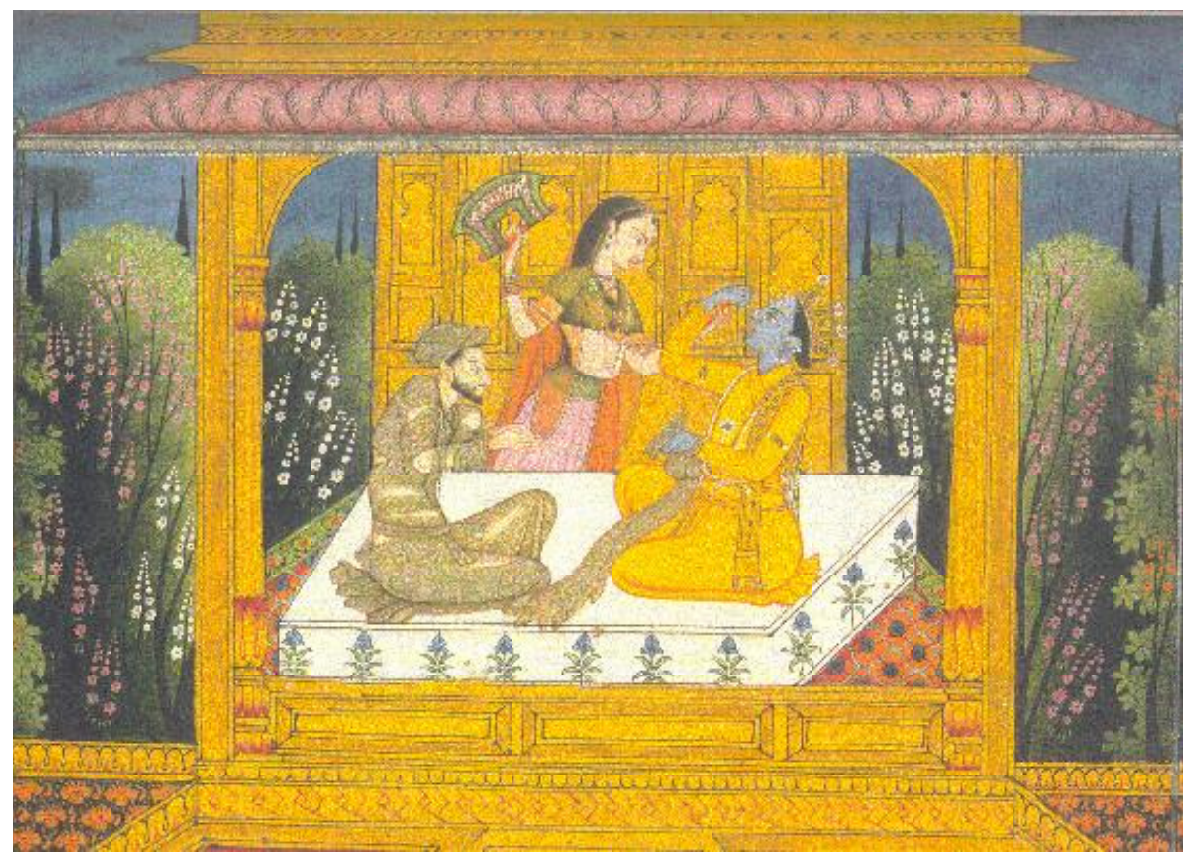

Fig.6 A golden yellow interior in a traditional miniature painting, Garhwal, Pahari. Courtesy: Barrister Mukundilal collection.

In the same way, degrees of surface will vary according to the tone of colour. The very pale yellows are to be found in many shades. There is Naples yellow that is almost a cream, and very useful for bright rooms. It looks very well with nearly everything. Then there is a pale primrose colour. It is the most comfortable colour, but is not a warming yellow as other shades of yellow. It is a cool colour and should not be used in dark places. Lime yellow is another cool yellow. It has a tone of green in it. Pale orange-yellow is the best to infuse a sunlight effect into a north 


\section{INTERNATIONAL JOURNAL Of RESEARCH -GRANTHAALAYAH

room, provided there is enough light to show it up. There is a pale golden yellow that is very warm in tone and is well used in a dark interior. It gives a pleasant glow and lights up at night better than most yellows, which are apt to disappear at night and looks white or cream.

The deeper yellows are not easy to use; greater care is needed to use them in any interior. Some yellows do not exist in the deeper shades at all. A deep lime yellow would become a green, because it is the green in it that makes it lime yellow, and to darken it, so much of green would be needed that it would almost become green. Similarly, when darkened, apricot yellow becomes a red and is no longer yellow.

The mustard yellow is very difficult to use. They are best avoided in bulk, but now and then a touch of it is useful. Old gold, which ranges from yellow to brownish-yellow, is a favourite with many interior designers. But to be successful, it must be used in good material only; such as silk, damask. Its use in cotton, khādi or wool begins giving a stuffy and sad look very quickly.

Emphasis is on the fact that yellow has too many varied shades, with each one a strong character and its effect. Great judgment must be used in taking the right shade according to the need of an interior.

\section{PURPLE}

In home decoration, purple needs to be used with a good deal of circumspection. The bluer purples can be used on staircase and landing walls where the rooms opening out have blue in abundance. Pale tones of blue-purple are really mauve, and are impossible to use in an interior unless copiously mixed with pink. Red purples are useful at times. At times, this colour supplies just that rich note which is often required. There is a purple that is almost slate, and it will be found very useful in decoration. It is almost a neutral tint, and makes an excellent background.

Copper or steel are the best metals for fittings in a purple interior, and, if plentiful, these will enliven the effect. If one has to use a purple paint in a scheme, one should understand an artist's palette rather than turning blindly to the house painter. It is so due to the fact that it is difficult to create good purples without special blues and pinks.

The purple shades can be very successful in interior decoration. It is simply a matter of the association of the right tints and right materials that makes for its success.

\section{RED}

No other colour can do what red can. It is also one of the colours which can clearly be seen from a long distance. It may be due to the high radiations it emits. These special properties are responsible for its use, in Indian art, to symbolize the intense emotions of anger and romance. And its clear visibility from long distances due to the high radiations it emits may be responsible for its use in Indian railways, traffic signals and as sign of danger. At times, in Indian art, red is also associated with royalty, auspiciousness, festivity and celebration. In terms of religion, it is linked with Goddess Durga. 


\section{INTERNATIONAL JOURNAL Of RESEARCH -GRANTHAALAYAH \\ A knowledge Repository}

Art

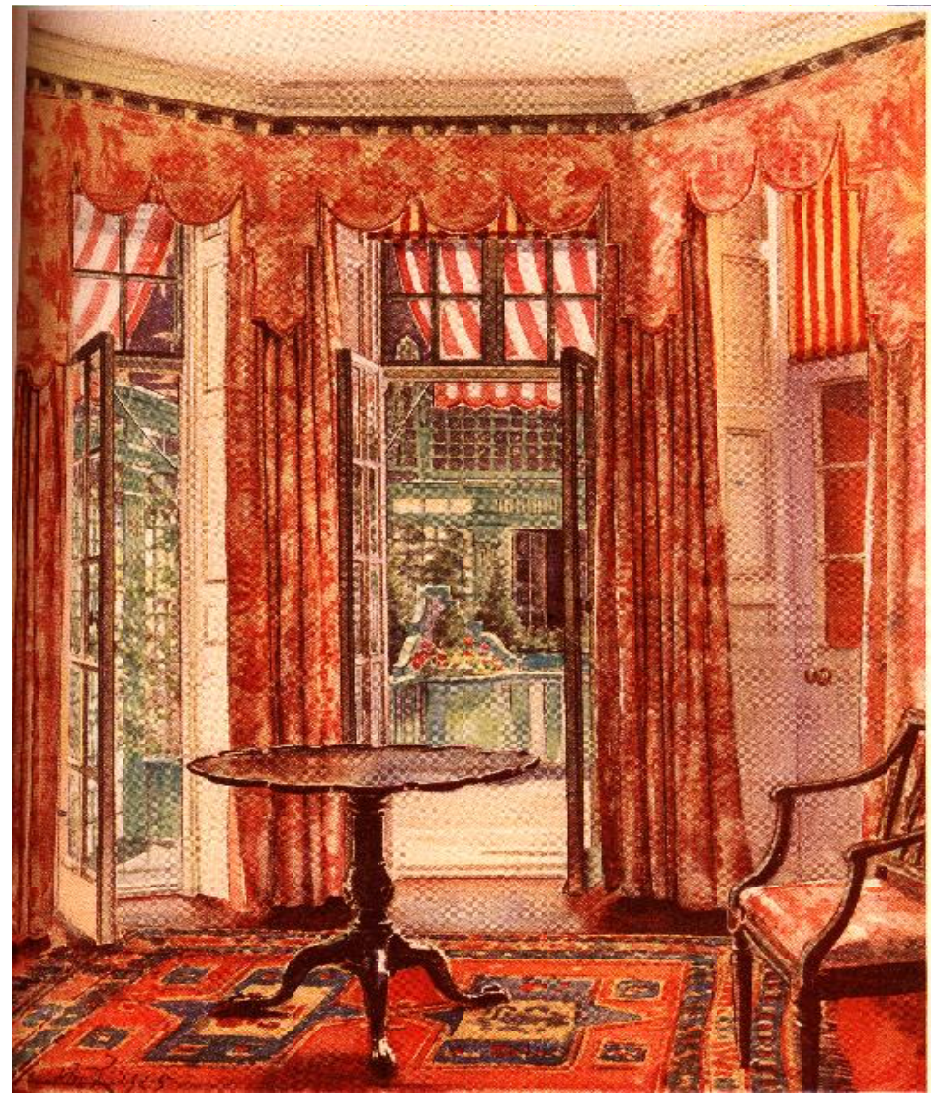

Fig.7 A room in varied tones of red. Picture by W.B.E. Ranken.

Originally from the book 'Colour and Interior Decoration' by Basil Ionides. Pub: Country Life Ltd., London, 1926.

The range of red begins with purple-red and ends in orange-red. The least oppressive reds are those with a blue tinge and the gayest are those going towards orange. If a red room is desired, it is best in crimson or rose-red. Bright scarlet-reds have their uses in an interior. Scarlet rescues a dull or gloomy colour from dullness quicker than any other colour. A dining or a spacious hall may look good in red but when it comes to a bedroom or a sitting room, these shades should be used only sparingly. Mostly, reds are lovely but needs to be sobered down by the use of other colours. An orange-red interior with soft ivory curtains and cushions or grey accessories is pleasing. Its effect will be heightened by the introduction of a good deal of polished brass copper. Terra-cotta red is another safe shade of red which can be applied in interiors demanding a country effect. Bright shades of red are to be avoided in large quantities in an interior where peace is desired; but they are equally lively and exhilarating where desired so. Such points are worth considering, as they fully illustrate the fact that it is the use, and not the colour, which is at fault when schemes go wrong. 


\section{INTERNATIONAL JOURNAL Of RESEARCH -GRANTHAALAYAH \\ A knowledge Repository}

Art

\section{CONCLUSION}

The association of a colour with particular emotion or mood is eternal, and that is why we have colour psychology, colour symbolism and colour therapy. For instance, white may have varied religious meaning or cultural significance but never can it be used to denote violence. This is due to the composition of light white is composed of. And it is this composition of colours which makes a science of them, while it is the timelessness of colours which makes an aesthetic of them. In short, the symbolic values, uses, likes and fashion of colours may keep changing but their identities will always remain intact. Thus, colours, when it comes to interior decoration or any other aspect of life, should be considered as subject of science and aesthetics so that their eternal effect may be remembered and the best decision may be taken.

\section{END NOTES:}

1. In Cornwall, UK, church Lezant has amazing slate tombs of the Trefusis family.

\section{REFERENCES}

1. Ionides, Basil. Colour and Interior Decoration. London: Country Life Ltd. 1926.

2. Beach, Milo Cleveland Beach. Mughal and Rajput Painting Volume 1.3 (The new Cambridge History of India). Cambridge: Cambridge University Press, September 1992.

3. Ganpataye, Pramod. A Guide to the Indian Miniatures. New Delhi: National Museum Institute, 1994.

4. Randhawa, M.S. Basohli Paintings. New Delhi: Director Publications Divisions, Ministry of Information \& Broadcasting, Government of India, 1959.

5. Pahari Paintings of the Gita Govind, Lalit Kala Series Portfolio No. 46, New Delhi: Lalit Kala Akademi.

6.http://www.metacafe.com/watch/10637614/chand_ne_kuch_kaha_dil_to_pagal_hai_hd_arabic _subtitle_by_rebel_angel/

7.http://ozfurnishing.en.alibaba.com/product/1427301928800136067/_054_elegant_living_room _sofa_set_solid_wood_carving_rococo_furniture_antique_sofas_center_table_and_squre_table.h tml

8. http://www.docxie.com/luxury-home-office-interior-designs-inspirations/gorgeous-homeoffice-design-ideas-with-mirrored-desk-and-acrylic-chair-featuring-beautiful-crystal-chandeliersand-white-fur-rug-and-complete-with-glamorous-corner-floor-mirror/ 